\title{
Stat-tracks and mediotypes: powerful tools for modern ichnology based on 3D models
}

\author{
Matteo Belvedere ${ }^{\text {Corresp.. }}{ }^{1}$ ， Matthew R Bennett ${ }^{2}$, Daniel Marty ${ }^{1}$, Marcin Budka ${ }^{2}$, Sally C Reynolds ${ }^{2}$, Rashid \\ Bakirov ${ }^{2}$ \\ ${ }^{1}$ Section d'archéologie et paléontologie, Paléontologie A16, Office de la Culture, Porrentruy, Canton Jura, Switzerland \\ 2 Institute for Studies in Landscape and Human Evolution, Faculty of Science and Tecnology, Bournemouth University, Poole, United Kingdom \\ Corresponding Author: Matteo Belvedere \\ Email address: matteo.belvedere@gmail.com
}

Vertebrate tracks are subject to a wide distribution of morphological types. A single trackmaker may be associated with a range of tracks reflecting individual pedal anatomy and behavioural kinematics mediated through substrate properties which may vary both in space and time. Accordingly, the same trackmaker can leave substantially different morphotypes something which must be considered in creating ichnotaxa. In modern practice this is often captured by the collection of a series of 3D track models. We introduce two concepts to help integrate these 3D models into ichnological analysis procedures. The mediotype is based on the idea of using statistically-generated threedimensional track models (median or mean) of the type specimens to create a composite track to support formal recognition of a ichno type. A representative track (mean and/or median) is created from a set of individual reference tracks or from multiple examples from one or more trackways. In contrast, stat-tracks refer to other digitally generated tracks which may explore variance. For example, they are useful in: understanding the preservation variability of a given track sample; identifying characteristics or unusual track features; or simply as a quantitative comparison tool. Both concepts assist in making ichnotaxonomical interpretations and we argue that they should become part of the standard procedure when instituting new ichnotaxa. As three-dimensional models start to become a standard in publications on vertebrate ichnology, the mediotype and stat-track concepts have the potential to help guiding a revolution in the study of vertebrate ichnology and ichnotaxonomy. 
1 Stat-tracks and mediotypes: powerful tools for modern

\section{2 ichnology based on 3D models}

3 Matteo Belvedere $^{l^{*}}$, Matthew R. Bennett ${ }^{2}$, Daniel Marty ${ }^{1}$, Marcin Budka ${ }^{2}$, Sally C. Reynolds ${ }^{2}$, Rashid

4 Bakirov $^{2}$

5

$6{ }^{1}$ Office de la Culture, Section d'archéologie et paléontologie, Paléontologie A16, Hôtel des Halles, P.O.

7 Box 64, 2900 Porrentruy 2, Switzerland

$8{ }^{2}$ Institute for Studies in Landscape and Human Evolution, Faculty of Science and Technology,

9 Bournemouth University, Fern Barrow, Poole, BH12 5BB, UK

10 Corresponding author:

11 Matteo Belvedere ${ }^{1}$

12 Email address: matteo.belvedere@gmail.com 


\section{Abstract}

14 Vertebrate tracks are subject to a wide distribution of morphological types. A single trackmaker

15 may be associated with a range of tracks reflecting individual pedal anatomy and behavioural

16 kinematics mediated through substrate properties which may vary both in space and time.

17 Accordingly, the same trackmaker can leave substantially different morphotypes something

18 which must be considered in creating ichnotaxa. In modern practice this is often captured by the

19 collection of a series of 3D track models. We introduce two concepts to help integrate these 3D

20 models into ichnological analysis procedures. The mediotype is based on the idea of using

21 statistically-generated three-dimensional track models (median or mean) of the type specimens to

22 create a composite track to support formal recognition of a ichno type. A representative track

23 (mean and/or median) is created from a set of individual reference tracks or from multiple

24 examples from one or more trackways. In contrast, stat-tracks refer to other digitally generated

25 tracks which may explore variance. For example, they are useful in: understanding the

26 preservation variability of a given track sample; identifying characteristics or unusual track

27 features; or simply as a quantitative comparison tool. Both concepts assist in making

28 ichnotaxonomical interpretations and we argue that they should become part of the standard

29 procedure when instituting new ichnotaxa. As three-dimensional models start to become a

30 standard in publications on vertebrate ichnology, the mediotype and stat-track concepts have the

31 potential to help guiding a revolution in the study of vertebrate ichnology and ichnotaxonomy.

\section{Introduction}

33 This paper uses a combination of dinosaur and human tracks to explore an emerging tool in

34 ichnology, namely the use of statistics-based virtual tracks (e.g., mean or median tracks) to

35 explore morphological variability (i.e., departures from typical or average morphology), and its 
36 potential role in ichnotaxonomy. The reader may be forgiven for questioning at the outset

37 however what dinosaur and human tracks have in common and why they appear together in the 38 same work? Even though such tracks are imprinted by completely different trackmakers and in

39 very different geological time periods, both are biogenic sedimentary structures that represent the 40 dynamic interaction of a foot (morphology + kinematics) with the substrate properties at the time 41 of formation (Padian \& Olsen, 1984; Marty, Strasser \& Meyer, 2009; Falkingham, 2014). Once

42 formed they may be affected and modified during taphonomy (e.g., Cohen et al., 1991; Scott et 43 al., 2007; Marty, Strasser \& Meyer, 2009; Scott, Renaut \& Owen, 2010) and diagenesis (Phillips 44 et al., 2007). So even where a track is imprinted by a single species of trackmaker the resulting 45 population of tracks may be very varied and in extreme cases are classified as different 46 morphotypes (e.g. Romilio et al., 2013). Accordingly, in the study of ichnites it is crucial to 47 understand and distinguish biomechanical, behavioural and preservation variants and to recognize 48 the range of features that do (and do not) correspond to the morphological record that a given 49 trackmaker's foot can make in the geological record. Despite being a complex biogenic 50 sedimentological structure, a track can often closely, although not perfectly, represent the 51 morphology of the trackmaker's autopodium, or portion thereof (i.e. proximal region of the 52 autopodium may not constitute parts of the palm or sole surface) allowing the study of the 53 geographical and/or temporal distribution of an ichnotaxon and of its trackmaker. Key features of 54 a dinosaur track, such as the digit (phalangeal) pads and claw impressions for example may not 55 be preserved in one single track (e.g. Razzolini et al., 2017), but different features may be 56 preserved in several different tracks along the length of a trackway, or across a given 57 ichnocoenosis. Understanding this variability lies at the heart of many ichnological studies, 58 especially when identification of the trackmaker is very complicated and speculative.

59 Traditionally, the study of vertebrate tracks has been addressed by a combination of detailed 
60 description, photography and in some cases by blending and overlapping track outlines (e.g., the

61 'composite tracks' in Olsen \& Baird, 1986). Digitization tools and procedures (e.g., optical laser

62 scanners, close-range photogrammetry, CT scans) have increased appreciably in recent years

63 whether generated by photogrammetry (e.g., Matthews, Noble \& Breithupt, 2016, and references

64 therein) or by laser scanning (e.g., Bates et al., 2008; Petti et al., 2008; Belvedere, Mietto \&

65 Ishigaki, 2010; Belvedere \& Mietto, 2010). The capture, presentation and analysis of 3D track

66 data has become increasingly standard in publications on vertebrate tracks and is now considered

67 by many to be an essential part of the ichnological tool kit, although there remains a body of

68 'traditionalists' who still hold to more conventional methods. Despite these differences most

69 would agree, however, that 3D data has a potentially revolutionary role in quantifying

70 morphological variability. In fact, Falkingham (2016, p.73) has commented on the difficulty of

71 applying objective methods to track outlines and basic descriptions and has emphasised "the

72 importance of ichnologists taking advantage of modern digitizing techniques in order to

73 communicate and share full three-dimensional (3-D) data". The use of multiple 3D track models

74 to explore morphological variation is increasingly common, but the tools to aid this remain in

75 their infancy. There has been a number of attempts recently to develop methods for creating 3D

76 mean or median tracks by co-registering multiple examples and computing mean depth (z) values

77 (e.g., Crompton et al., 2012; Bennett et al., 2016a,b). We explore this further here via a series of

78 case studies using one of these approaches based on the freeware DigTrace (Budka et al., 2016).

79 To assist in this, we introduce the idea of 'stat-track' namely a statistical-based (e.g., mean,

80 median, standard deviation) track created from a population of co-registered tracks that allow one

81 to explore variability via measures of central morphological tendency and the 'mediotype', the

82 mean and median stat-track generated from type specimens (e.g., holotype, paratypes) of a given

83 ichnotaxon. It is analogous to the term 'digitype' introduced by (Adams et al., 2010) to describe

84 the digital facsimile of a type specimen, in the same way that 'plastotype' (a cast of the primary 
85 type, Morningstar, 1924) can be considered equivalent to the original specimen.

\section{Methodology}

87 Trackway and track terminology and labelling of the dinosaur trackways from the Ajoie

88 ichnocoenosis follows standard approaches (Marty, 2008; Marty et al., 2010; Marty, Falkingham

$89 \&$ Richter, 2016). Human track terminology follows Bennett \& Morse (2014). The geological

90 context and applied documentation methodology of the studied material are presented in

91 Supplemental Information.

\section{$92 \quad$ 2.1 Digital methods}

93 Digital 3D track data are obtained from a range of optical laser scanners and increasingly via

94 digital photogrammetry (Falkingham, 2012; Bennett \& Morse, 2014). Bennett et al. (2013)

95 provide a comparative review of data derived from optical laser scanners and photogrammetry

96 concluding that while the former gives more accurately scaled results the latter is operationally

97 much easier.

98 Traditionally, tracks have been analysed by comparison of track or outlines and/or the placement

99 and comparison of inter-landmark distances, at their simplest these may be length and width

100 measurements. Landmark placement occurs in the field by the operator selecting measurement

101 points. In the case of a 2D photograph, outline drawing, or $3 \mathrm{D}$ surface this is usually in the form

102 of a physically located and labelled landmark. Either way basic dimensions for multiple tracks

103 can be obtained, size distribution considered, and centres of central tendency calculated.

104 Especially, but not only (e.g., Rodrigues \& Santos, 2004; Belvedere, 2008; Castanera et al., 2013;

105 Lallensack, van Heteren \& Wings, 2016), in human ichnology, the digital placement whether on a

106 2D or 3D image also allows Cartesian coordinates to be recorded and subject geomorphometric 
107 analysis via a Procrustes analysis or similar approach (e.g., Berge, Penin \& Pellé, 2006; Hammer

108 \& Harper, 2007; Bennett et al., 2009). Hatala et al. (2016) have advocated the use of what they 109 call 'areas of interest' as an alternative approach; in truth, these are just geometrically placed 110 landmarks across the plantar surface of a track.

111 The idea of 'whole-track' analysis, introduced by Crompton et al. (2012) in their analysis of the 112 Laetoli hominin tracks (Tanzania), requires the registration (Goshtasby, 2005) of one or more 113 tracks, to allow areas of anatomical similarity to be overlapped as defined by the user, or by some 114 form of statistical parameter (e.g., least squares). The term 'registration' refers to the process of 115 transforming one track to a 'source' (or 'master') track, such that the three-dimensional 116 morphology of other tracks is optimally overlapped. Once a succession of tracks has been 117 registered, it is possible to compare the depth along the ' $z$ '-axis values for each track, and thereby 118 compute measures of central tendency for the population of registered tracks. A mean, or median, 119 track can be created in this way and they provide, in theory at least, a more accurate topological 120 representation of the trackmaker's foot impression than any one individual track. Being aware of

121 the possibility that some features can be washed out by this process, the occurrence of peculiar 122 characteristics in the mean and median tracks is providing evidence of the importance of those 123 recurrent features. If interested only in the morphology of the foot, only the best tracks of the 124 trackway should be considered, as those with a very different preservation (e.g., with extensive 125 collapsing of the track walls) are influencing the resulting mean track and may bias the entire 126 analysis. A mean track, in fact, includes all intra-track variability within in a trackway caused, for 127 example, by behaviour, variation in gait or variation in rheological properties of the substrate 128 along a trackway (Morse et al., 2013; Razzolini et al., 2014). It therefore draws out the recurring 129 topological (i.e., depth variation) track morphology, which by inference in theory at least should 130 give insight into the morphological feature of the autopodium and, by comparison, into the 
131 biomechanical signature left by the trackmaker's mode of gait.

132 A method to register the plantar pressure records based on statistical parametric mapping (SPM)

133 was developed by Pataky \& Goulermas (2008), and termed by the authors pedobarographic

134 Statistical Parametric Mapping (pSPM). Registrations were achieved by various automated

135 algorithms using a progressive approach in which tracks are registered first to an initial track (the

136 first in the series) and then re-registered to an initial mean track. Different registration methods

137 were compared by Pataky, Goulermas \& Crompton (2008), who observed that manual methods

138 were found to be as accurate as the automated ones when averaged between operators. Therefore,

139 a pSPM-based approach has started being used by researchers (e.g., Crompton et al., 2012; Morse

140 et al., 2013; Bates et al., 2013). This approach, however, is not without its limitations, when

141 applied to a wider range of tracks: the main issue is the need of a smooth and relatively similar

142 topology across a range of tracks to obtain an automated registration of the tracks. In reality,

143 fossil tracks are complex structures that can contain forms, which vary between tracks, which

144 may interfere with automated registration. To use pSPM the researcher has to intervene on the

145 track topology by removing such distractions through cropping a track by elevation thus to focus

146 solely on the interpreted plantar (or palm, if on a forelimb) surface. The limitations in the manual

147 registration tools in $\mathrm{pSPM}$, the absence of a simple user interface and the availability of the

148 pSPM source code led Budka et al. (2016) to create the freeware DigTrace (www.digtrace.co.uk)

149 which caters for the registration of tracks, comparison and computation of measures of central

150 tendency using a landmark-matching process (for details see Bennett et al., 2016a,b).

\section{$151 \quad 2.2$ Mediotype and stat-tracks}

152 Stat-track. A stat-track (statistical based tracks) is defined as the virtual specimens generated

153 from the co-registration of 3D models of two or more tracks. Stat-tracks can be used to make 
154 morphological comparisons.

155 There are currently at least two published software solutions for the co-registration of tracks as

156 outlined above (i.e., DigTrace, and the unpublished pSPM code of Pataky \& Goulermas, 2008).

157 Here we use the freeware DigTrace (Budka et al., 2016) which is based on the co-registration of

158 tracks via user-defined anatomical or morphological landmarks, essentially the matching of

159 similar points (however defined) on two tracks. Once two or more tracks are co-registered in the

$160 \mathrm{x}-\mathrm{y}$ plane using either rigid (i.e. dependant on the shape and size of the specimen, optimal for

161 comparing tracks of the same trackmaker or of similar size) or affine transformations (i.e.

162 dependant only on the shape of the specimen and not on the size, optimal for comparing tracks

163 from different trackmakers or with very different dimensions), the software computes measures

164 of central tendency for the depth or z-values. DigTrace allows the generation of six different stat-

165 tracks: mean, median, maximum and minimum differences, standard deviation and point-to-point

166 comparison, all of which can be exported as point clouds (.asc or .csv files). It is important to

167 emphasise that DigTrace is one of several potential software solutions that achieve similar ends.

168 Mediotype. The mediotype is a specific case of stat-track. It is defined as the mean and/or median

169 stat-track (as from the Latin prefix medio-) generated from the co-registration of type specimens

170 (holotype, paratype(s) and/or other type tracks).

171 In general, stat-tracks allow one to make reproducible comparisons of a track sample, based on

172 the actual three-dimensional morphology of the track and not just on bi-dimensional

173 (interpretative outline) drawings, descriptions and/or photos. Mediotypes, mean and median stat-

174 tracks allow the study of a morphology derived from several different tracks, whereas the use of

175 deviation-based stat-tracks (e.g., minimum, maximum or standard deviation) allows the

176 identification of intra-sample variance with the sampled tracks (even between different 
177 mediotypes or mean-media start-tracks). These results can be used as a basis for more detailed

178 descriptions and comparisons with other material and ichnotaxa. Software such as DigTrace also

179 allow the comparison between different mediotypes and makes direct comparisons of holotypes

180 with other type material. One can also explore extramorphological variations (e.g., displacement

181 rims, collapsing substrate, dragging of the digits, etc.) on the overall shape of the track.

182 It is important to remember, however, that the researcher must know the purpose of the 183 investigation as this determines both the sample selection and the interpretation of the resulting 184 stat-track. For example, if one is interested in instituting a new ichnotaxon, he has to underline 185 the key features and to see if they are present in different footprints; however, only the best tracks 186 should be used (i.e., the type specimens) and the mediotype should highlight the common 187 features. If a sample of unselected tracks (including also the poor ones) is chosen for the same 188 purpose, the mean and median stat-tracks will more likely blur out the key features and create a 189 useless virtual track. Also, locomotion-oriented studies may not benefit from the use of stat-tracks 190 as they rely more on the autopodium/substrate interaction than on the autopodium morphology. It 191 is also worth mentioning that the quality of 3D models (e.g., resolution, presence of noise, holes 192 etc.) can influence the generation and interpretation of stat-tracks (and mediotypes), and it is in 193 the responsibility of the researcher to select only the models that are suitable for his research and 194 to try to avoid very low resolution or very noisy meshes.

195 It is also important to remember that the stat-track outputs (i.e. the .asc and .csv files) are 196 visualized in DigTrace as false-colour maps. In order to keep the distinction between the actual 197 specimens and the virtual tracks the researcher should use a different colour scheme to illustrate 198 the stat-tracks. Here we have used a 'rainbow' scheme to visualize the mean and median stat199 tracks and the mediotypes, and a black and white scheme to illustrate the standard-deviation, min 200 and max stat-track, however there is no rule, and the files can even be imported in a different 
201 software (e.g. CloudCompare) to create different colour schemes, as long as the researcher 202 explain the colour scheme used.

\section{Case studies}

204 Here, we present some applications of the stat-track and mediotype concepts to show its

205 appliance to morphological analyses of similar sauropod tracks from the same ichnocoenosis but

206 with a very different size (3.1), to the morphological study of a track population of the same

207 trackmaker species (3.2 Laetoli), to the erection of new ichnotaxa (3.3.1 Jurabrontes

208 curtedulensis), and to the validation through comparison of new ichnotaxa (3.3.2

209 Megalosauripus transjuranicus). The IDs of the tracks used to generate each stat-track and 210 mediotype of this work are listed in Table 1.

\section{$211 \quad 3.1$ Late Jurassic sauropod tracks (Ajoie ichnocoenosis, Switzerland)}

212 With this case study, we show how stat-tracks can be used to compare tracks from the same

213 ichnocoenosis characterized by similar morphologies but (very) different sizes in order to identify

214 if there were affinities among the tracks and if it was possible to determine a single or multiple

215 trackmakers independently from the dimensions of the tracks.

216 Sauropod tracks are very common in the Late Jurassic Ajoie ichnocoenosis (Canton Jura, NW

217 Switzerland) and vary in size from tiny (pes length $<25 \mathrm{~cm}$ ) to large (PL $>75 \mathrm{~cm})$ (Marty, 2008;

218 Marty et al., 2010, 2017; Belvedere et al., 2016). The tiny (PL $<25 \mathrm{~cm}$, the smallest around 10

$219 \mathrm{~cm}$ in mean pes length) and small $(25<\mathrm{PL}<50 \mathrm{~cm})$ tracks present very strong similarities in pes

220 digit configuration and position, as well as in overall pes (and manus) morphology, and were

221 therefore chosen for this analysis. Only the best-preserved (grade $>2$ on the scale of Belvedere \& 
222 Farlow, 2016) pes tracks available in the PALA16 collection (see Supplemental Information)

223 were digitized and used. This decision was taken to maximise the quality of the comparison from

224 a morphological point of view, for which purpose the highest morphological detail possible was

225 needed. A total of ten tiny and nine small pes tracks were used to generate the mean stat-tracks

226 for each size class (Figs. 1A, 1B). Accordingly, in the following comparison, variations due to

227 different individual trackmakers, to different locomotion styles, and due to differences in

228 substrate properties are included. The registration contours superimposition (Fig. 1C) and

229 maximum stat-tracks (Fig. 1D) both show pronounced similarities amongst the tracks. The

230 differences are isolated only to the depth, especially of digit I and II (the darker areas in the Fig.

231 1D). The resemblance is so similar that, without taking into account the considerable size

232 difference (the largest is around 4 times longer than the smallest), all these tracks could fall in the

233 range of intraspecific or even intra-trackway variation (Razzolini et al., 2014, 2017; Lallensack,

234 van Heteren \& Wings, 2016), despite the fact they are the result of the comparison of different

235 trackways (different animals, trackmakers) and from different ichnoassemblages and track levels.

236 To highlight also the slightest differences, which might be mitigated by using the mean stat-tracks

237 based on a relatively large sample size, the best-preserved tracks for each size class (BSY008-

238 S25-RP6 for the tiny and BSY008-S12-RP2 for the small tracks) were also compared (Figs. 1E,

$2391 \mathrm{~F})$, showing an even greater similarity in the general morphology, with the only substantial

240 difference related to the depth, especially in the heel and digit I areas (darker areas in Fig. 1F).

241 To conclude, the studied sauropod pes tracks from the Ajoie ichnocoenosis are extremely similar

242 and consistent in shape, despite the different weight (due to the difference in size) of their

243 trackmakers, different animals having left the tracks, and despite (slight) differences in substrate

244 properties (different track levels). The generation of stat-tracks highlights differences in

245 impression depth of the digits (as expected given the pronounced difference in weight and the 
246 similar substrate), the position and orientation of the claw marks, which result in the mean stat-

247 tracks in a slightly obliterated and vague claw mark for both the small and tiny tracks. Another

248 difference is the size of the depression behind digit I, in the proximal part of the track, which is

249 slightly bigger and elongated in the small tracks when compared to the tiny ones (Fig. 1D). The

250 same difference in the proximal (heel) area is present in the best-track comparison, whereas the

251 difference in the position of digits and claws is minimal. This implies that the substrate had a very

252 similar rheological response to the different weights of the animals to preserve the same degree of

253 details in two different track size ranges. Also, it is concluded that the two size classes clearly

254 belong to the same ichnogenus and ichnospecies (yet to be defined). Moreover, stat-tracks can

255 better support the presence of different size (age) classes of a single trackmaker species than the

256 simple description of the presence of 'similar' morphologies in different size classes (Belvedere

257 et al., 2016).

258 3.2 Pliocene hominin tracks (Laetoli, Tanzania)

259 Stat-tracks have recently been used to examine the Laetoli tracks and make comparisons with the

260 tracks made by other hominin species (Crompton et al., 2012; Bennett et al., 2016a,b). In this

261 case study, we extend the use of mean stat-tracks by including the additional data recently

262 published from sites adjacent to the original trackways (Masao et al., 2016), highlighting also the

263 importance and opportunity of using digital models produced and shared by other researchers.

264 The inclusion of this new data adds significantly to the mean forms produced to date.

265 Laetoli is probably the most iconic of all human trackways and was first discovered and 266 excavated in the late 1970s and now dated to 3.66 Ma (Deino, 2011). For many people they 267 provide one of the earliest direct sources of evidence for hominin bipedalism (Leakey \& Hay, 
268 1979; Leakey, 1981; Leakey \& Harris, 1987), although the degree to which the biomechanics of

269 the trackmaker resemble those of modern humans has been subject to extensive debate and

270 remains controversial (e.g., Bennett et al., 2016a; Hatala et al., 2016). The year 2016 saw the

271 number of individual trackmakers at Laetoli rise from three, with only one useable trackway, to a

272 total of in excess of 5 trackways. The discovery of additional tracks published in 2016 (Masao et

273 al., 2016) has further increased the value of this already important site, particularly since the new

274 tracks yield a more varied insight into the potential height and weight of the trackmakers assumed

275 by most researchers to be Australopithecus afarensis (White \& Suwa, 1987; Harcourt-Smith, 276 2005).

277 Formal ichnotaxonomy has not been widely applied to hominin tracks, however the Laetoli tracks

278 were used for this purpose by (Meldrum et al., 2011) (Praehominipes laetoliensis), following the

279 lead set by (Kim et al., 2008) who used the tracks preserved in volcanic mud (Lockley et al.,

280 2007; Schmincke et al., 2009), and under cover in a museum at Acahualinca (Nicaragua) to

281 define the ichnotaxa Hominipes modernus for modern human tracks. The value of these

282 ichnotaxa per se is perhaps questionable, although it is correct to question why hominin tracks

283 should be an ichnological exception. Human track morphology varies with age, gender, and body

284 mass. The latter is a function of nutrition and environmental/climatic conditions and body size

285 ratios (i.e., foot length to height) are known to vary also with ethnicity/race. They may also vary

286 between different hominin species with both biomechanical and anatomical variations possible

287 (Bennett \& Morse, 2014). Mean tracks for the G1-trackway at Laetoli were first calculated by

288 Crompton et al. (2012) using pSPM and subsequently by Bennett et al. (2016a,b) using DigTrace.

289 One potential area of subjectivity is the placement of the landmarks used for registration. Fig. 2

290 addresses this issue; each of the mean tracks presented (Fig. 2A-K) was generated by an

291 independent operator and the similarity between each of these mean tracks is clear. It would also

292 be possible to generate a mean track on the basis of these means thereby reducing operator 
293 variance further (Fig. 2L). In addition, Bennett et al. (2016b) used DigTrace to separate the

294 composite tracks of the G2-trackway which is composed of superimposed tracks made by at least

295 two (maybe three) trackmakers walking in line. Using a combination of individual tracks from

296 the G1, G3, L8, M9, and TP2 trackways, and published by different authors (Bennett et al.,

297 2016a; Masao et al., 2016), it is possible to establish a mean stat-track for each trackway (Fig 3A-

298 E) to supplement the formal ichnotaxa proposed by Meldrum et al. (2011) accounting different

299 sizes and morphologies of the same hominin ichnoassociation. Fig. 3F shows a mean mediotype

300 for the G1-Trackway at Laetoli based on the 11 topologically most complete tracks. In this case,

301 the value in a mediotype lies in providing a scientifically agreed mean or representative track

302 with which both intra- and crucially inter-site comparisons can be made (Bennett et al., 2016b). A

303 revision of $P$. laetoliensis should therefore include the recent discoveries and, if worth, add new

304 type specimens and create a mediotype for the ichnotaxon. Using the mean stat-track generated

305 from the various tracksites, allowed a meaningful comparison with a modern human footprint

306 (Fig. 3G). This provides continued perspective on the degree of medial transfer in the latter stages

307 of stance within the Australopithecines (Bennett et al., 2016a; Hatala et al., 2016).

308 3.3 Late Jurassic theropod tracks (Ajoie ichnocoenosis, Switzerland)

309 These examples serve to underline the ichnotaxonomical potential of mediotypes and stat-tracks.

310 In the focus are two new, recently described, ichnotaxa: Jurabrontes curtedulensis. (Marty et al.,

311 2017) and Megalosauripus transjuranicus (Razzolini et al., 2017), both erected on Late Jurassic

312 tracks from the Ajoie ichnocoenosis (Canton Jura, NW Switzerland).

\section{3.3.1 Jurabrontes curtedulensis}

314 This is a giant $(\mathrm{PL}>50 \mathrm{~cm})$ new theropod ichnogenus and ichnospecies, based on very well- 
315 preserved material (grade 2.5 to 3 of Belvedere \& Farlow, 2016). Four type-specimens (holotype,

3163 paratypes) were used to define this ichnotaxon (Fig. 4A), and for the first time the publication

317 was accompanied by a mediotype generated through DigTrace. Different approaches were

318 considered to generate the mean tracks: the mediotype (Fig. 4B) was based on the four type

319 specimens, which differ especially regarding their impression depth due to differences in

320 substrate properties and thickness. In the mediotype, all key features (including the very faint

321 impression of digit III's proximal phalangeal pad) of the description of the ichnotaxon are visible,

322 confirming the morphological observations and descriptions made with standard methods (direct

323 observation of the specimen, outline drawings, depth maps). A second set of mean and median

324 stat-tracks (Fig. 4C) was generated from the holotype trackway to determine intra-trackway

325 variability. The holotype trackway is composed of 11 clear and continuous tracks, and the

326 mediotype was calculated using the seven digitized tracks (either gathered in 2011 with a

327 laserscanner or in 2016 through photogrammetry).

328 The derived stat-tracks show a very conservative shape and highlights all the key features of the 329 new ichnotaxon, despite the variation in depth and preservation of the individual tracks and even 330 by incorporating tracks that were not good enough to be considered as type-specimens.

\section{3.3.2 Megalosauripus transjuranicus}

332 This new ichnospecies was erected based on large theropod tracks that were frequently found on

333 tracksites and levels of the Ajoie ichnocoenosis. This ichnotaxon presents some peculiar

334 characteristics (e.g., the large proximal pad of digit IV) that identify it as a new ichnospecies

335 (Fig. 5A) of the ichnogenus Megalosauripus (Razzolini et al., 2017).

336 Even though the seven type specimens are from different tracksites and track levels (i.e., they are

337 not coeval but may have been left within some hundred to ten thousand years of difference), and 
338 the fact that also the preservation varies (one of the paratypes is preserved as a natural cast), the

339 mediotype (Fig. 5B) exhibits the key features of the ichnospecies. The standard deviation stat-

340 track (Fig. 5C) supports these similarities, as most the of the differences among the type

341 specimens is located in cracks, which are not present in all samples, and areas that are affected by

342 a high degree of mobility of the tridactyl foot during locomotion (e.g., digit III distal part, or digit

343 IV width) (Belvedere, 2008; Castanera et al., 2013; Lallensack et al., 2016).

344 An important application of stat-tracks is to validate ichnotaxonomical assignations or

345 relationships by comparing stat-tracks and mediotypes of different specimens and ichnotaxa. The

346 ichnogenus Megalosauripus has often been used as wastebasket in ichnotaxonomy, and it

347 includes tracks that are quite different one from another. In addition, the ichnogenus has issues

348 about its validity (see Lockley, Meyer \& Santos, 2000; Thulborn, 2001 for the Megalosauripus-

349 Megalosauropus dispute). To show the potential of stat-track- and mediotype-based analyses, a

350 comparison is shown here (Fig. 6) between the M. transjuranicus mean mediotype (Fig. 5B) and

351 two other tracks, one belonging to the known Megalosauripus ichnospecies M. teutonicus (Fig.

352 6A), and the other to a Megalosauripus isp. track (Fig. 6C) from the Late Jurassic of Morocco. In

353 the first comparison, the standard deviation stat-track (Fig. 6B) shows only few similarities; it

354 shows a lower deviation (lighter colour) around digit IV and digit II, whereas digit III presents

355 higher differences, and it's almost impossible to identify. Digit IV seems to maintain the shape of

356 the M. transjuranicus mediotype: this is probably due to a combination of similarities between

357 the two samples, but highly biased by the completely different preservation of the two specimens.

358 Considering all these aspects, the comparison through stat-track supports and validates the

359 interpretation of Razzolini et al. (2017) in the attribution of material from the Ajoie ichnocoenosis

360 to a new ichnospecies different from M. teutonicus (Keaver \& Lapparent, 1974). Despite the fact

361 that they are assigned to the same ichnogenus and that the best available specimens were used,

362 the comparison clearly indicates that these two tracks do not have so much in common. This 
363 underlines how important it is that ichnotaxa are erected only on particularly well-preserved

364 tracks, and that a detailed revision of the known ichnotaxa is needed. The second comparison

365 (Fig. 6D) emphasizes the great resemblance between tracks from the Ajoie ichnocoenosis and

366 from Morocco. The standard deviation stat-track shows marked differences (very dark) in the

367 position of the digit III claw impression (the dark triangle ahead of the digit), which is isolated

368 and not connected to digit III in the Moroccan track, and in the depth of the inner part of digit III.

369 This can be explained by the different depth of the two digits, and by the much steeper walls of

370 the Moroccan specimen. Another difference occurs in the position and shape of digit II, that can

371 be explained with the fact that in the Moroccan tracks digit II shows some dragging marks. Some

372 differences occur also in digit IV, where the less distal phalangeal pads seem different from $M$.

373 transjuranicus. As for digit III this can be explained with the different depth and width of digit IV

374 of the 2 tracks (Moroccan track is deeper, the Swiss is wider) and with the steeper track walls of

375 the Moroccan specimen. Despite these differences, which is worth noticing are limited to few

376 millimetres (Fig. 6D), there is a high similitude between the tracks suggesting that not only the

377 interpretation of the track as Megalosauripus isp. (Belvedere, 2008; Belvedere, Mietto \&

378 Ishigaki, 2010) was correct, but that, pending further analyses on a larger track sample, the

379 Moroccan tracks could be addressed at least as $M$. cf. transjuranicus. This use of stat-tracks and

380 mediotypes has a great development potential not only for ichnotaxonomical comparisons and

381 attribution, but also to more accurately study the ichnotaxa present in different geographical areas

382 or to better determine the time range and geographical distribution of a given ichnotaxon.

\section{Discussion}

384 The case studies illustrate the potential of stat-tracks and mediotypes to help explore variability in 385 track morphology. Essentially they help to: (1) define in a new three-dimensional way the 
386 'average' or 'typical' morphology within a given sample of tracks, extremely important for

387 ichnotaxonomical studies; (2) quantify the distribution of morphological variability within a

388 population around the mean/median and identify which morphological/anatomical areas of a

389 track are responsible for that variability; (3) compare both qualitatively and statistically 'typical'

390 morphological distributions from different sites, ages, and/or trackmakers; (4) define individual,

391 potentially important, departures (i.e., specific cases) from a typical morphology; and (5) explore

392 how morphological variability changes with changes in biomechanics or substrate. Whatever

393 methodology used to co-register tracks, the potential to enhance ichnological analysis is clear and

394 we argue that this procedure should become a standard part of ichnological research to

395 complement, rather than substitute, the traditional and well-established ichnological analyses.

396 That is not to say that there aren't some challenges here. There is an ever-present risk that

397 important but under represented features in a track are 'washed-out' by the averaging process and

398 there will always be a role for considering, and perhaps emphasising individual tracks in making

399 an interpretation. Equally there is a risk of 'forcing' different tracks into a single population. In

400 the case of DigTrace careful consideration of the standard error, based on the fit of all the placed

401 landmarks, is essential and statistical tools to map 95\% confidence measures are in development.

402 In fact, pSPM explicitly allows statistical assessments of this sort (Crompton et al., 2012). We

403 would argue therefore that the benefits outweigh the potential risks of 'averaging' affects, which

404 can also be mitigated by a careful selection of the specimens to investigate.

405 The study of similar tracks from the same locality or a selected stratigraphic range is reinforced

406 by the use of stat-tracks that allows reliable and repeatable comparisons among different

407 specimens. As such, population studies have the possibility to move towards a more accurate

408 identification of the relationship between different trackmakers, as presented in Case Study 3.1

409 and 3.2. The possibility to gather the characteristic features of several different specimens in one 
410 and the same mean or median stat-track (or mediotype if referred to type material) allows

411 mitigating, when not eliminating, extramorphological features from the description of the typical

412 characteristics of a given track sample, thus providing a more accurate morphotype. The three-

413 dimensional comparison of different morphotypes using their mean stat-tracks will make analyses

414 of ichnoassemblages and ichnocoenoses more objective and trust worthier as they will be less

415 affected by a researcher's subjective interpretation of the tracks.

416 The study of the Laetoli tracks (Case Study 3.2) highlights the quality and the reliability of the

417 landmark placing, which generates higher quality morphometrical analyses through a geometric

418 morphometric application. Moreover, the possibility of working with such a reliable mediotype

419 for the hominin tracks, allows a formal basis for interspecies comparisons at least at the genus

420 level, for example comparing tracks made by Homo with those of Australopithecines, and, not

421 last, for more detailed evolutionary studies.

422 Whether mediotypes have a role in formal ichnotaxonomy needs to be considered.

423 Ichnotaxonomy is not without its philosophical and methodological problems because of the

424 morphological variability often present within tracks and the potential for multiple track

425 morphologies to be associated with a single trackmaker. In fact, it might be fair to say the

426 ichnology community is polarised between those that favour formal classification of tracks and

427 those that don't and who emphasis the biomechanical and behavioural importance of tracks over

428 their formal identification or trackmaker identification (e.g., Gatesy \& Falkingham, 2017). It is

429 worth however exploring the potential significance of mediotypes in terms of ichnotaxonomy.

430 The Linnaean classification of fossil vertebrate tracks (footprints) is an agreed, but often

431 uncertain practice (Demathieu \& Demathieu, 2003). Given the peculiar nature of tracks as the

432 result of the combined interaction of foot morphology, substrate properties, locomotion and

433 behaviour, unlike conventional palaeontology finding a 'morphologically-perfect' specimen is 
434 quite rare. Morphological and taxonomical studies should be carried out therefore on the largest

435 number of (morphologically well-preserved) specimens available (Sarjeant, 1989), in order to

436 better understand the influence of extramorphological factors on the definition and description of

437 an ichnotaxon. In the best cases ichnotaxonomical descriptions are accompanied by photographs

438 and illustrations of the type-specimens. These however, do not always represent the sum of the

439 characteristics of an ichnotaxon, but simply the features of each type specimen included. We

440 argue that the use of $3 \mathrm{D}$ data may assist in correcting this omission.

441 The usual way of giving names to tracks consists of a binomial combination of the (ichno)genus

442 and (ichno)species names (Bertling et al., 2006). As for other zoological disciplines, the

443 nomenclature process follows rules established by the International Commission of Zoological

444 Nomenclature (ICZN) published in its code (ICZN, 1999). The ICZN code (1999) defines the

445 holotype as "the single specimen upon which a new nominal species-group taxon is based in the

446 original publication" (ICZN, 1999, Art. 73) and paratypes as "any remaining specimens of the

447 type series” (ICZN, 1999, Art 73, Recommendation 73D).

448 Due to this complexity, vertebrate ichnogenera and ichnospecies should be defined on

449 morphological criteria of the track (Thulborn, 1990) rather than on the supposed systematic

450 affinity of the trackmaker, and they may change if the animal's behaviour changes (Sarjeant,

451 1990). Moreover, it is good practice to capture all potential ichnotaxa formed by a single

452 trackmaker. For these reasons the ICZN code, since 1979, has exempted ichnotaxa from

453 zoological taxonomy, stating that an ichnotaxon does not compete in priority with a taxon

454 established for an animal, even if the animal may have formed the track (ICZN, 1999, Art. 23.7).

455 The erection of a new ichnotaxon should also consider the 'Ten palaeoichnological

456 commandments' of Sarjeant (1989). These commandments stress above all: the importance of

457 basing a new taxon on trackways (i.e., a track population) and not on isolated tracks (I); support 
458 for a new ichnotaxon should be based on detailed illustrations, photos, and digital models (IV, V);

459 and provide unambiguous diagnoses of the trackmaker where possible (VIII). It follows that an

460 ichnotaxon should present the main morphological characteristics and the key features that

461 distinguish it from any other. This should be based on creating, from different type specimens

462 (holotypes and paratypes), an average description including the key features, which cannot

463 normally be supported by a single illustration or photograph as it is an abstraction based on

464 multiple tracks. Therefore, the diagnosis of a new (ichno)taxon is the description of the key

465 features present in all type specimens, with remarks on the most characteristic ones. Illustrations

466 (outline drawings, photographs, 3D models) on the other hand, only illustrate distinct specimens,

467 which may not include all of the described typical features. In a certain sense, while the

468 description makes an average description of the specimen, illustrations of single specimens only

469 represent some peculiar aspects. Despite being formally right, in a complex and very qualitative

470 discipline as vertebrate ichnology, the attribution of a track to a certain ichnotaxa is often based

471 on (highly subjective) morphological and graphical comparisons. Moreover, there might be

472 differences amongst the holotype and the paratypes related to differences in substrate properties

473 and other extramorphological factors that can make the comparison with other specimens even

474 more difficult. Baird and Olsen (1986) tented a solution for this issue, by creating 'composite

475 tracks' putting together the most important features of various key specimens of a single

476 ichnotaxon (e.g. Atreipus), but the output was still a bi-dimensional outline drawing.

477 Over the last years, the use of three-dimensional models has spread a lot in ichnology and is

478 already becoming a standard for sharing data, also thanks to the diffusion on cloud services (e.g.,

479 Figshare). Nonetheless, so far only a few publications have provided extensive digital data at the

480 moment of the institution of a new ichnotaxon (e.g., Razzolini et al., 2017; Marty et al., 2017).

481 However, despite carrying more information than bi-dimensional images, three-dimensional

482 models (as photographs and outline drawings) only represent a specific specimen, which may not 
483 contain all of the key features of the ichnotaxon. The use of mediotypes is a powerful tool for

484 ichnologists to summarize and illustrate all key features of an ichnotaxon and to statistically

485 support the observations made on the actual specimens and the descriptions of an ichnotaxon.

486 The development of such tools like DigTrace and other similar examples, the diffusion of the

487 concept and use of mediotypes together with the increased application of three-dimensional and

488 quantitative methodologies in vertebrate ichnology can, in the near future, allow a new

489 quantitative and statistically-based approach in ichnotaxonomy.

490 It might also soon be possible to establish variation thresholds between studied specimen(s) and

491 the reference ichnotaxon (holotype, paratypes, mediotypes). Therefore, if the specimen's values

492 are within the thresholds it can be assigned to the reference ichnotaxon with a higher confidence,

493 whereas when the values don't pass the threshold, the specimen shouldn't be referred to that

494 ichnotaxon. Given the complexity of track identification and interpretation, a purely quantitative

495 and statistical attribution is not reliable, as it does not consider those very punctual differences

496 caused by for example taphonomy (Marty, Strasser \& Meyer, 2009) or excavation (partially

497 present track fills) and weathering damages, which can be observed only in the actual specimen

498 (in some cases not even in the digital replicas). Therefore, these quantitative tools and analyses

499 should always be accompanied by a classical descriptive and qualitative approach, that will

500 consider those features that do not affect the ichnotaxonomical interpretation, and, eventually

501 serve to identify some of the extramorphologies as observed on 3D models. We suggest that

502 mediotypes and the other stat-tracks have the potential to have a deep impact on ichnotaxonomy,

503 although, as 'plastotype', 'digitype' has not yet been formalized in the ICZN, and can at the

504 moment not be solely used to erect a new taxon.

\section{Conclusions}


506 The concept of the stat-track (and mediotype) formalises a current trend in vertebrate ichnology,

507 namely the description and comparison of morphological variability via 3D track data. It is based

508 on the idea of the co-registration of different tracks to create mean/median representations of a

509 track population, to allow comparisons of those mean/median tracks between sites, substrates and

510 trackmakers and crucially to allow departures from mean/median tracks to be examined. Stat-

511 tracks also permit the comparison though different statistical approaches, of distinct tracks and

512 the generation of virtual models of the differences among specimens, which can be used to

513 quantify and, also, visualize the similarities among different specimens. There are a number of

514 tools, including DigTrace used here, available to aid this type of analysis and we encourage the

515 development of further tools. We argue that mediotypes increase the value of ichnotaxonomical

516 interpretations. Consequently, mediotypes are produced from type specimens only and represent

517 the best three-dimensional approximation of the diagnosis of a given ichnotaxon. Whether the

518 mediotype concept is validated by the ICZN, or not, like the 'digitype' concept, in the future we

519 believe it will have a deep impact on ichnotaxonomy and should become a standard for the

520 description of new and validation of existing ichnotaxa. Finally, stat-tracks have an important role

521 in understanding and crucially documenting the morphological variability of tracks produced by a

522 single trackmaker under varying conditions and circumstances, and this will enhance the 523 understanding of the locomotive and behavioural range of a given ichnospecies.

\section{Acknowledgements}

525 We thank Novella L. Razzolini, Christian A. Meyer, Diego Castanera, and Michela Contessi for

526 discussions on the idea of the mediotype concept and about its possible use in ichnotaxonomy.

527 Some special thanks go to. $\mathrm{MBv}$ and $\mathrm{DM}$ thank all technicians, photographers, geometers, 528 drawers, collection managers, and preparators of the PALA16 that were involved during the 
529 excavation and documentation of the tracksites and during the set-up and organization of the 530 track collection, as well as the scientific staff of the PALA16 and JURASSICA Muséum for 531 various stimulating discussions and valuable input. The National Museum of Kenya is 532 acknowledged with thanks for providing access to the first generation of cast of the Laetoli tracks 533 in 2008. MRB would also like to thank Robin Crompton, Karl Bates and Todd Pataky for useful 534 discussion about whole foot methods. A copy of DigTrace can be obtained from 535 www.digtrace.co.uk. Finally, we thank the editor Jérémy Anquetin, and the journal reviewers 536 Anthony Romilio and Sebastian Voigt or their insightful feedback and comments that 537 considerably improved the quality of this manuscript, and the 4 anonymous reviewers of the 538 previous submission. In addition, we wish to thank all the participants at the ICCI 2017 meeting, 539 which, together with the reviewers, helped in developing the mediotype and stat-tracks concepts.

\section{References}

541 Adams TL., Strganac C., Polcyn MJ., Jacobs LL. 2010. High resolution three-dimensional laser-

542 scanning of the type specimen of Eubrontes (?) glenrosensis Shuler, 1935, from the Comanchean

543 (Lower Cretaceous) of Texas: implications for digital archiving and preservation. Palaeontologia

544 Electronica 13:1-12.

545 Bates KT., Collins D., Savage R., McClymont J., Webster E., Pataky TC., D’Aout K., Sellers

546 WI., Bennett MR., Crompton RH. 2013. The evolution of compliance in the human lateral mid-

547 foot. Proceedings of the Royal Society B: Biological Sciences 280:20131818. DOI:

$548 \quad 10.1098 /$ rspb.2013.1818.

549 Bates KT., Rarity F., Manning PL., Hodgetts D., Vila B., Oms O., Galobart À., Gawthorpe RL., 550 Galobart A., Gawthorpe RL. 2008. High-resolution LiDAR and photogrammetric survey of the 551 Fumanya dinosaur tracksites (Catalonia): implications for the conservation and interpretation of 552 geological heritage sites. Journal of the Geological Society 165:115-127. DOI: 10.1144/0016$55376492007-033$.

554 Belvedere M. 2008. Ichnological researches on the Upper Jurassic dinosaur tracks in the 555 Iouaridène area (Demnat, Central High-Atlas, Morocco). 
556 Belvedere M., Farlow JO. 2016. A numerical scale for quantifying the quality of preservation of 557 vertebrate tracks. In: Falkingham PL, Marty D, Richter A eds. Dinosaur Tracks - The next steps. 558 Bloomington and Idianapolis: Indiana University Press, 92-99.

559 Belvedere M., Marty D., Stevens KA., Ernst S., Razzolini NL., Paratte G., Cattin M., Lovis C., 560 Meyer CA. 2016. Minute sauropod tracks from the Late Jurassic of Canton Jura: babies or 561 dwarfs? Morphological and behavioural evidences. In: Abstract Volume 14th Swiss Geoscience 562 Meeting. Geneva, 132.

563 Belvedere M., Mietto P. 2010. First evidence of stegosaurian Deltapodus footprints in North 564 Africa (Iouaridène Formation, Upper Jurassic, Morocco). Palaeontology 53:233-240. DOI: 565 10.1111/j.1475-4983.2009.00928.x.

566 Belvedere M., Mietto P., Ishigaki S. 2010. A Late Jurassic diverse ichnocoenosis from the 567 siliciclastic Iouaridène Formation (Central High Atlas, Morocco). Geological Quarterly 54:367568380.

569 Bennett MR., Falkingham P., Morse SA., Bates K., Crompton RH. 2013. Preserving the 570 Impossible: Conservation of Soft-Sediment Hominin Footprint Sites and Strategies for Three571 Dimensional Digital Data Capture. PLoS ONE 8. DOI: 10.1371/journal.pone.0060755.

572 Bennett MR., Harris JWK., Richmond BG., Braun DR., Mbua E., Kiura P., Olago D., Kibunjia 573 M., Omuombo C., Behrensmeyer AK., Huddart D., Gonzalez S. 2009. Early Hominin Foot 574 Morphology Based on 1.5-Million-Year-Old Footprints from Ileret, Kenya. Science 323:1197575 1201. DOI: 10.1126/science. 1168132.

576 Bennett MR., Morse SA. 2014. Human Footprints: Fossilised Locomotion? Cham: Springer 577 International Publishing. DOI: 10.1007/978-3-319-08572-2.

578 Bennett MR., Reynolds SC., Morse SA., Budka M. 2016a. Footprints and human evolution: 579 Homeostasis in foot function? Palaeogeography, Palaeoclimatology, Palaeoecology 461:214580 223. DOI: 10.1016/j.palaeo.2016.08.026.

581 Bennett MR., Reynolds SC., Morse SA., Budka M. 2016b. Laetoli's lost tracks: 3D generated 582 mean shape and missing footprints. Scientific Reports 6:21916. DOI: 10.1038/srep21916. 
583 Berge C., Penin X., Pellé É. 2006. New interpretation of Laetoli footprints using an experimental 584 approach and Procrustes analysis: Preliminary results. Comptes Rendus - Palevol 5:561-569. 585 DOI: 10.1016/j.crpv.2005.09.001.

586 Bertling M., Braddy SJ., Bromley RG., Demathieu GR., Genise J., Mikuláš R., Nielsen JK., 587 Nielsen KSS., Rindsberg AK., Schlirf M., Uchman A. 2006. Names for trace fossils: a uniform 588 approach. Lethaia 39:265-286. DOI: 10.1080/00241160600787890.

589 Budka M., Bakirov R., Deng S., Falkingham PL., Reynolds SC., Bennett MR. 2016. DigTrace 590 Academic.www.digtrace.co.uk.

591 Castanera D., Pascual C., Razzolini NL., Vila B., Barco JL., Canudo JI. 2013. Discriminating 592 between medium-sized tridactyl trackmakers: tracking ornithopod tracks in the base of the 593 cretaceous (Berriasian, Spain). PLoS ONE 8:e81830. DOI: 10.1371/journal.pone.0081830.

594 Cohen A., Lockley M., Halfpenny J., Michel AE. 1991. Modern Vertebrate Track Taphonomy at 595 Lake Manyara, Tanzania. Palaios 6:371. DOI: 10.2307/3514964.

596 Crompton RH., Pataky TC., Savage R., D’Août K., Bennett MR., Day MH., Bates K., Morse S., 597 Sellers WI. 2012. Human-like external function of the foot, and fully upright gait, confirmed in 598 the 3.66 million year old Laetoli hominin footprints by topographic statistics, experimental 599 footprint-formation and computer simulation. Journal of the Royal Society, Interface / the Royal 600 Society 9:707-719. DOI: 10.1098/rsif.2011.0258.

601 Deino AL. 2011. ${ }^{40} \mathrm{Ar} /{ }^{39}$ Ar Dating of Laetoli, Tanzania. In: Harrison T ed. Paleontology and 602 Geology of Laetoli: Human Evolution in Context Vol.1. Springer Netherlands, 77-97. DOI: 603 10.1007/978-90-481-9956-3_4.

604 Demathieu G., Demathieu P. 2003. Concerning the erection of ichnogenera and ichnospecies in 605 vertebrate ichnotaxonomy. Ichnos 9:117-121. DOI: 10.1080/10420940290208153.

606 Falkingham PL. 2012. Acquisition of high resolution three-dimensional models using free, open607 source, photogrammetric software. Palaeontologia Electronica 15:1T:15p.

608 Falkingham PL. 2014. Interpreting ecology and behaviour from the vertebrate fossil track record. 609 Journal of Zoology 292:222-228. DOI: 10.1111/jzo.12110. 
610 Falkingham PL. 2016. Applying objective methods to subjective track outlines. In: Falkingham

611 PL, Marty D, Richter A eds. Dinosaur Tracks - The next steps. Bloomington and Idianapolis:

612 Indiana University Press, 72-81.

613 Gatesy SM., Falkingham PL. 2017. Neither bones nor feet: track morphological variation and

614 “preservation quality.” Journal of Vertebrate Paleontology:e1314298. DOI:

$61510.1080 / 02724634.2017 .1314298$.

616 Goshtasby AA. 2005. 2-D and 3-D image registration for medical, remote sensing, and industrial 617 applications. Wiley-Interscience publication.

618 Hammer Ø., Harper DAT. 2007. Paleontological Data Analysis. Malden, MA, USA: Blackwell 619 Publishing. DOI: 10.1002/9780470750711.

620 Harcourt-Smith WEH. 2005. Did Australopithecus afarensis make the Laetoli footprint trail?

621 New insights into an old problem. American Journal of Physical Anthropology 126:112.

622 Hatala KG., Roach NT., Ostrofsky KR., Wunderlich RE., Dingwall HL., Villmoare BA., Green 623 DJ., Harris JWK., Braun DR., Richmond BG. 2016. Footprints reveal direct evidence of group 624 behavior and locomotion in Homo erectus. Scientific reports 6:28766. DOI: 10.1038/srep28766.

625 ICZN. 1999. International Code of Zoological Nomenclature. Fourth Edition. London: The 626 International Trust for Zoological Nomenclature.

627 Keaver M., de Lapparent AF. 1974. Les traces de pas de dinosaures du Jurassique de Barkhausen 628 (Basse Saxe, Allemagne). Bullettin de la Societé Géologique de France, Série VIII 16:516-525.

629 Kim JY., Kim KS., Lockley MG., Matthews N. 2008. Hominid ichnotaxonomy: an exploration of 630 a neglected discipline. Ichnos 15:126-139. DOI: 10.1080/10420940802467868.

631 Lallensack JN., van Heteren AH., Wings O. 2016. Geometric morphometric analysis of 632 intratrackway variability: A case study on theropod and ornithopod dinosaur trackways from 633 Münchehagen (Lower Cretaceous, Germany). PeerJ 4:e2059. DOI: 10.7717/peerj.2059.

634 Leakey MD. 1981. Tracks and tools. Philosophical Transactions of the Royal Society of London 635 B, Biological Sciences 292:95-102. 
636 Leakey MD., Harris JM. 1987. Laetoli: A Pliocene Site in Northern Tanzania. Claredon Press,

637 Oxford University Press.

638 Leakey MD., Hay RL. 1979. Pliocene footprints in the Laetoli beds at Laetoli, northern Tanzania. 639 Nature 278:317-323.

640 Lockley MG., Meyer CA., Santos VF. 2000. Megalosauripus and the problematic concept of 641 megalosaur footprints. Gaia 15:313-337.

642 Lockley MG., Vasquez RG., Espinoza E., Lucas SG. 2007. Notes on a famous but "forgotten" 643 human footprint site from the Holocene of Nicaragua. In: Lucas SG, Spielmann JA, Lockley MG 644 eds. Cenozoic Vertebrate Tracks and Traces. New Mexico Museum of Natural History and 645 Science Bulletin 42:97-102.

646 Marty D. 2008. Sedimentology, taphonomy, and ichnology of Late Jurassic dinosaur tracks from 647 the Jura carbonate platform (Chevenez - Combe Ronde tracksite, NW Switzerland): insights into 648 the tidal-flat palaeoenvironment and dinosaur diversity, locomotion, and palaeoecolog. GeoFocus $64921: 1-278$.

650 Marty D., Belvedere M., Meyer CA., Mietto P., Paratte G., Lovis C., Thüring B. 2010.

651 Comparative analysis of Late Jurassic sauropod trackways from the Jura Mountains (NW 652 Switzerland) and the central High Atlas Mountains (Morocco): implications for sauropod 653 ichnotaxonomy. Historical Biology 22:109-133. DOI: 10.1080/08912960903503345.

654 Marty D., Belvedere M., Razzolini NL., Lockley MG., Paratte G., Cattin M., Lovis C., Meyer 655 CA. 2017. The tracks of giant theropods (Jurabrontes curtedulensis ichnogen. \& ichnosp. nov.) 656 from the Late Jurassic of NW Switzerland: palaeoecological \& palaeogeographical implications. 657 Historical Biology:1-29. DOI: 10.1080/08912963.2017.1324438.

658 Marty D., Falkingham PL., Richter A. 2016. Dinosaur track terminology: a glossary of terms. In: 659 Falkingham P, Marty D, Richter A eds. Dinosaur Tracks - The next steps. Bloomington and 660 Idianapolis: Indiana University Press, 399-402.

661 Marty D., Strasser A., Meyer CA. 2009. Formation and taphonomy of human footprints in 662 microbial mats of present-day tidal-flat environments: implications for the study of fossil 663 footprints. Ichnos 16:127-142. DOI: 10.1080/10420940802471027. 
664 Masao FT., Ichumbaki EB., Cherin M., Barili A., Boschian G., Iurino DA., Menconero S., 665 Moggi-Cecchi J., Manzi G. 2016. New footprints from Laetoli (Tanzania) provide evidence for 666 marked body size variation in early hominins. eLife 5:e19568. DOI: 10.7554/eLife.19568.

667 Matthews N., Noble T., Breithupt BH. 2016. Close-Range photogrammetry for 3D ichnology: the 668 basics of photogrammetric ichnology. In: Falkingham PL, Marty D, Richter A eds. Dinosaur 669 Tracks - The next steps. Bloomington and Idianapolis: Indiana University Press, 28-55.

670 Meldrum DJ., Lockley MG., Lucas SG., Musiba C. 2011. Ichnotaxonomy of the Laetoli 671 trackways: The earliest hominin footprints. Journal of African Earth Sciences 60:1-12. DOI: 672 10.1016/j.jafrearsci.2011.01.003.

673 Morningstar H. 1924. Catalogue of type fossils in the Gological Museum at the Ohio State 674 Unviersity. Ohio Journal of Science 24:31-64.

675 Morse SA., Bennett MR., Liutkus-Pierce C., Thackeray F., McClymont J., Savage R., Crompton 676 RH. 2013. Holocene footprints in Namibia: the influence of substrate on footprint variability. 677 American Journal of Physical Anthropology 151:265-279. DOI: 10.1002/ajpa.22276.

678 Olsen PE., Baird D. 1986. The ichnogenus Atreipus and its significance for Triassic 679 biostratigraphy. In: Padian K ed. The Beginning of the age of Dinosaurs. Cambridge University 680 Press, 61-87.

681 Padian K., Olsen PE. 1984. The fossil trackways Pteraichnus: not pterosaurian, but crocodilian. 682 Journal of Paleontology 58:178-184.

683 Pataky TC., Goulermas JY. 2008. Pedobarographic statistical parametric mapping (pSPM): A 684 pixel-level approach to foot pressure image analysis. Journal of Biomechanics 41:2136-2143. 685 DOI: 10.1016/j.jbiomech.2008.04.034.

686 Pataky TC., Goulermas JY., Crompton RH. 2008. A comparison of seven methods of within687 subjects rigid-body pedobarographic image registration. Journal of Biomechanics 41:3085-3089. 688 DOI: 10.1016/j.jbiomech.2008.08.001.

689 Petti F., Avanzini M., Belvedere M., De Gasperi M., Ferretti P., Girardi S., Remondino F., 690 Tomasoni R. 2008. Digital 3D modelling of dinosaur footprints by photogrammetry and laser 
691 scanning techniques: integrated approach at the Coste dell'Anglone tracksite (Lower Jurassic,

692 Southern Alps, Northern Italy). Studi Trentini di Scienze Naturali, Acta Geologica 83:303-315.

693 Phillips PL., Ludvigson GA., Matthew Joeckel R., González LA., Brenner RL., Witzke BJ. 2007.

694 Sequence stratigraphic controls on synsedimentary cementation and preservation of dinosaur

695 tracks: example from the lower Cretaceous, (Upper Albian) Dakota Formation, Southeastern

696 Nebraska, U.S.A. Palaeogeography, Palaeoclimatology, Palaeoecology 246:367-389. DOI:

697 10.1016/j.palaeo.2006.10.013.

698 Razzolini NL., Belvedere M., Marty D., Paratte G., Lovis C., Cattin M., Meyer CA. 2017.

699 Megalosauripus transjuranicus ichnosp. nov. A new Late Jurassic theropod ichnotaxon from NW

700 Switzerland and implications for tridactyl dinosaur ichnology and ichnotaxomy. PLOS ONE

701 12:e0180289. DOI: 10.1371/journal.pone.0180289.

702 Razzolini NL., Vila B., Castanera D., Falkingham PL., Barco JL., Canudo JI., Manning PL.,

703 Galobart À. 2014. Intra-trackway morphological variations due to substrate consistency: the El

704 Frontal dinosaur tracksite (Lower Cretaceous, Spain). PLoS ONE 9:e93708. DOI:

705 10.1371/journal.pone.0093708.

706 Rodrigues LA., Santos VF dos. 2004. Sauropod Tracks - a geometric morphometric study. In:

707 Elewa AMT ed. Morphometrics. Berlin, Heidelberg: Springer-Verlag, 129-142.

708 Romilio A., Tucker RT, Salisbury SW. 2013. Re-evaluation of the Lark Quarry dinosaur tracksite

709 (late Albian-Cenomanian Winton Formation, central-western Queensland, Australia): no longer a

710 stampede? Journal of Vertebrate Paleontology 33:102-120. DOI:

$711 \quad 10.1080 / 02724634.2012 .694591$

712 Sarjeant WAS. 1989. "Ten Palaeoichnlogical Commandments": a standardized procedure for the

713 description of fossil vertebrate footprints. In: Gillette DD, Lockley MG eds. Dinosaur Tracks and

714 Traces. Cambridge: Cambridge University Press, 369-370.

715 Sarjeant WAS. 1990. A name for the trace of an act: approaches to the nomenclature and

716 classification of fossil vertebrate footprints. In: Carpenter K, Currie PJ eds. Dinosaur

717 systematics: perspectives and approaches. Cambridge: Cambridge University Press, 299-307.

718 Schmincke H-U., Kutterolf S., Perez W., Rausch J., Freundt A., Strauch W. 2009. Walking 
719 through volcanic mud: the 2,100-year-old Acahualinca footprints (Nicaragua). Bulletin of 720 Volcanology 71:479-493. DOI: 10.1007/s00445-008-0235-9.

721 Scott JJ., Buatois LA., Mángano G., Genise JF., Melchor RN. 2007. Biogenic activity, trace 722 formation, and trace taphonomy in the marginal sediments of saline, alkaline lake Bogoria, 723 Kenya Rift Valley. In: Bromley RG, Buatois LA, Mángano G, Genise JF, Melchor RN eds.

724 Sediment-organism interactions: a multifaceted ichnology. SEPM Special Publication, 88, 309725330.

726 Scott JJ., Renaut RW., Owen RB. 2010. Taphonomic controls on animal tracks at saline, alkaline 727 lake Bogoria, Kenya Rift Valley: impact of salt efflorescence and clay mineralogy. Journal of 728 Sedimentary Research 80:639-665. DOI: 10.2110/jsr.2010.057.

729 Thulborn T. 1990. Dinosaur tracks. London: Chapman \& Hall.

730 Thulborn T. 2001. History and nomenclature of the theropod dinosaur tracks Bueckeburgichnus 731 and Megalosauripus. Ichnos 8:207-222. DOI: 10.1080/10420940109380188.

732 White TD., Suwa G. 1987. Hominid footprints at Laetoli: Facts and interpretations. American 733 Journal of Physical Anthropology 72:485-514. DOI: 10.1002/ajpa.1330720409. 


\section{Figure 1}

Example of a stat-track-based morphological comparison based on tiny and small sauropod tracks from the Ajoie ichnocoenosis.

(A) Mean stat-track of tiny sauropod tracks based on 10 specimens with a mean pes length of $11.6 \mathrm{~cm}$. Dark blue indicates the highest part, dark red the deepest part of the tracks. Scale bar: $10 \mathrm{~cm}$. (B) Mean stat-track of small sauropod tracks based on 9 specimens with a mean pes length of $36.9 \mathrm{~cm}$. Dark blue indicates the highest part, dark red the deepest part of the tracks. Scale bar: $10 \mathrm{~cm}$. (C) Superimposition of mean stat-tracks contours of the tiny (black) and small (red). (D) Maximum difference stat-track between the mean stat-tracks. The colours quantify the deviation between the models along the z-axis (values in $\mathrm{mm}$ ). The highest differences are concentrated in the depth and position of digits I and II. (E) Superimposition of contours of the tiny (black) and small (red) best tracks. (F) Maximum difference stat-track between the best tracks. The darker the colour, the larger the difference. The colours quantify the deviation between the models along the z-axis (values in $\mathrm{mm}$ ). The biggest difference is located on the position and depth of digit I and digit II claw marks, and on the depth of digit I. "I" and "II" indicate digit I and digit II, respectively 

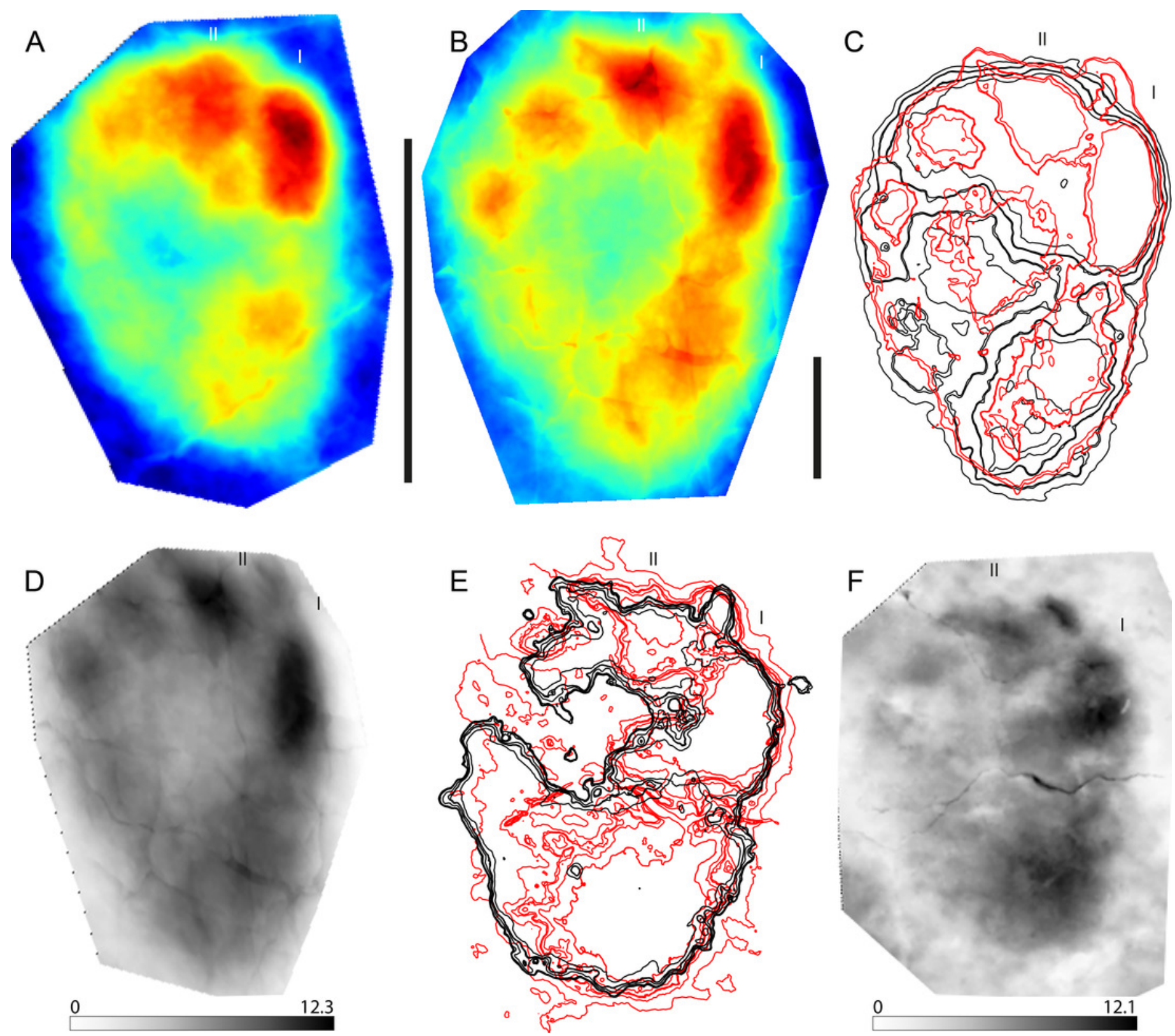
Figure 2

A series of eight contour maps for means stat-tracks of the G1-Trackway generated by different operators

(A-K) Seven operators were asked independently to create a mean track using DigTrace from

11 individual tracks. (L) The variation between these mean tracks is small and operator variance can be removed completely by creating a 'super' mean combining each individual mean stat-track. Contour interval is $1 \mathrm{~mm}$. See Table 1 for more information of the specimens used. 

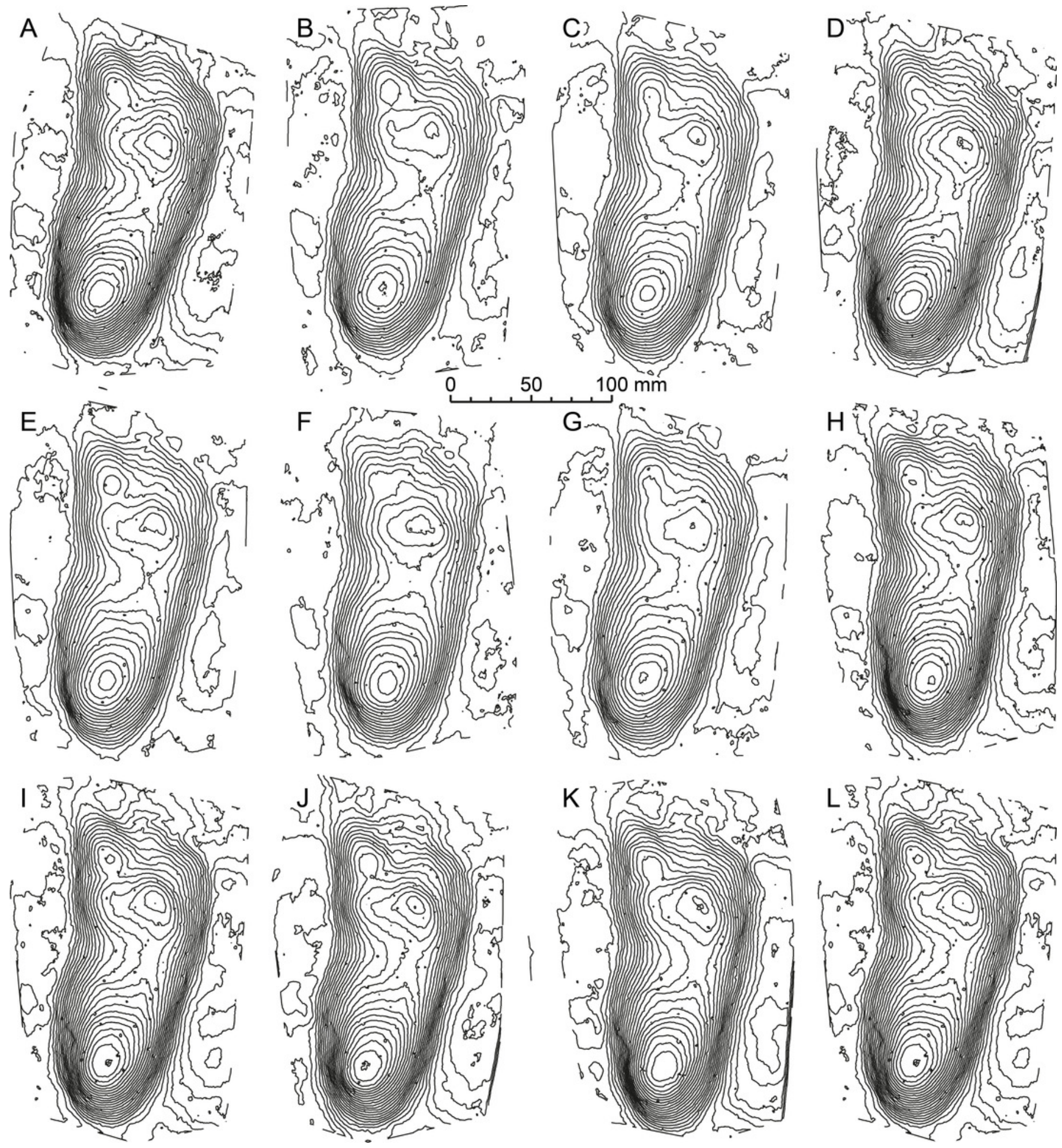


\section{Figure 3}

Mean stat-tracks for hominin tracks at Laetoli

The trackmaker is generally accepted to have been Australopithecus afarensis. (A) G1 trackway. (B) G3 trackway. (C) L8 trackway. (D) M9 trackway. (E) TP2 trackway. Fig 3A to 3E are all illustrated at the same scale. (F) Mean stat-track of Laetoli tracks, which could be used as mediotype in a future revision of Praehominipes laetoliensis. (G) Comparison between the Laetoli mediotype (red) and a modern human track (black). Note that the comparison is scale-free. See Table 1 for more information of the specimens. 

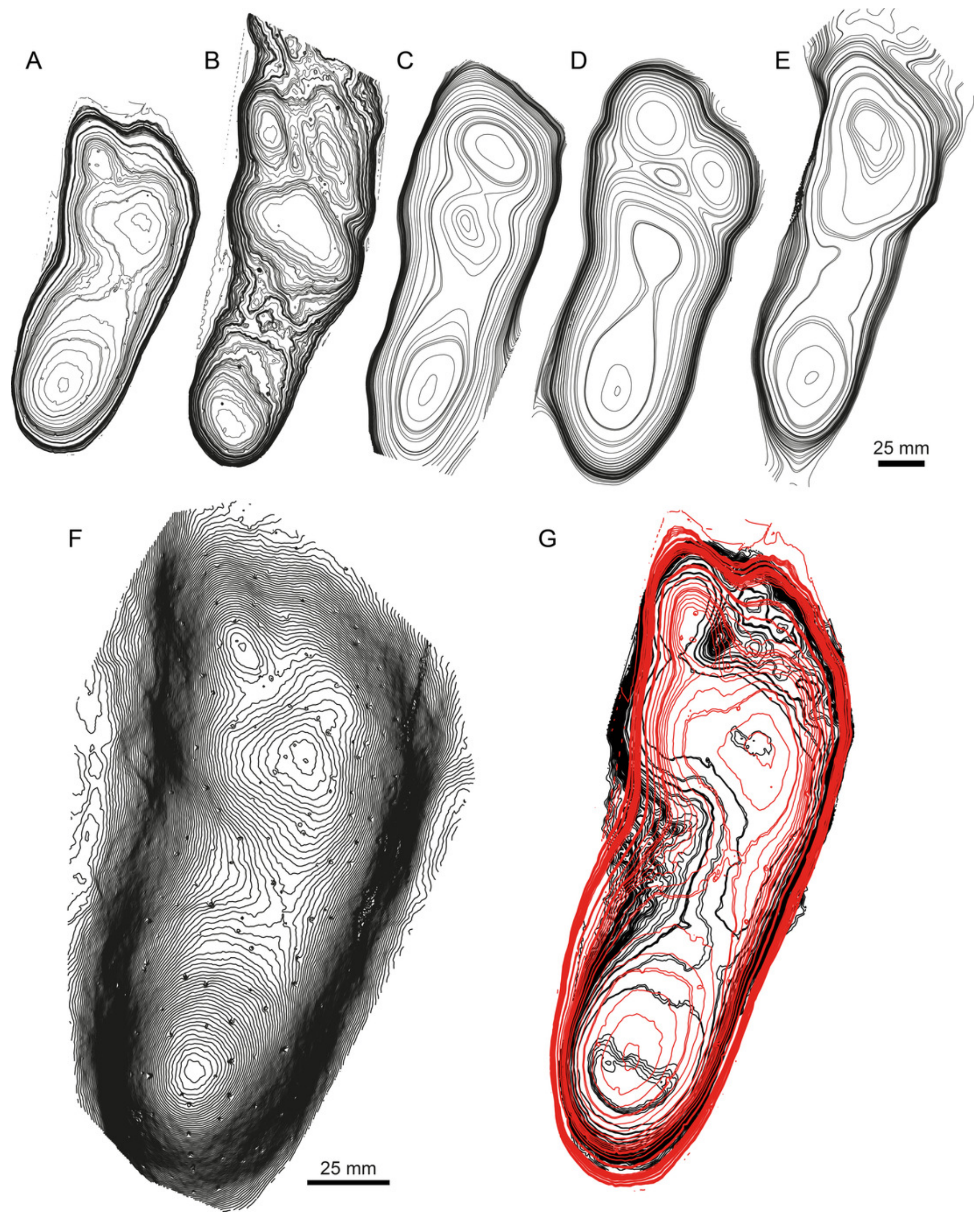


\section{Figure 4}

Jurabrontes curtedulensis holotype and mediotypes.

(A) Photograph of the holotype (SCR1500-T1-L8). Scale bar $20 \mathrm{~cm}$. (B) Mediotype generated from the 4 type specimens. (C) Mean stat-track generated from 7 tracks of the trackway including also the holotype and two of the paratypes. See Table 1 for more information of the specimens used. "II", "III" and "IV" indicate digit II, digit III and digit IV, respectively.
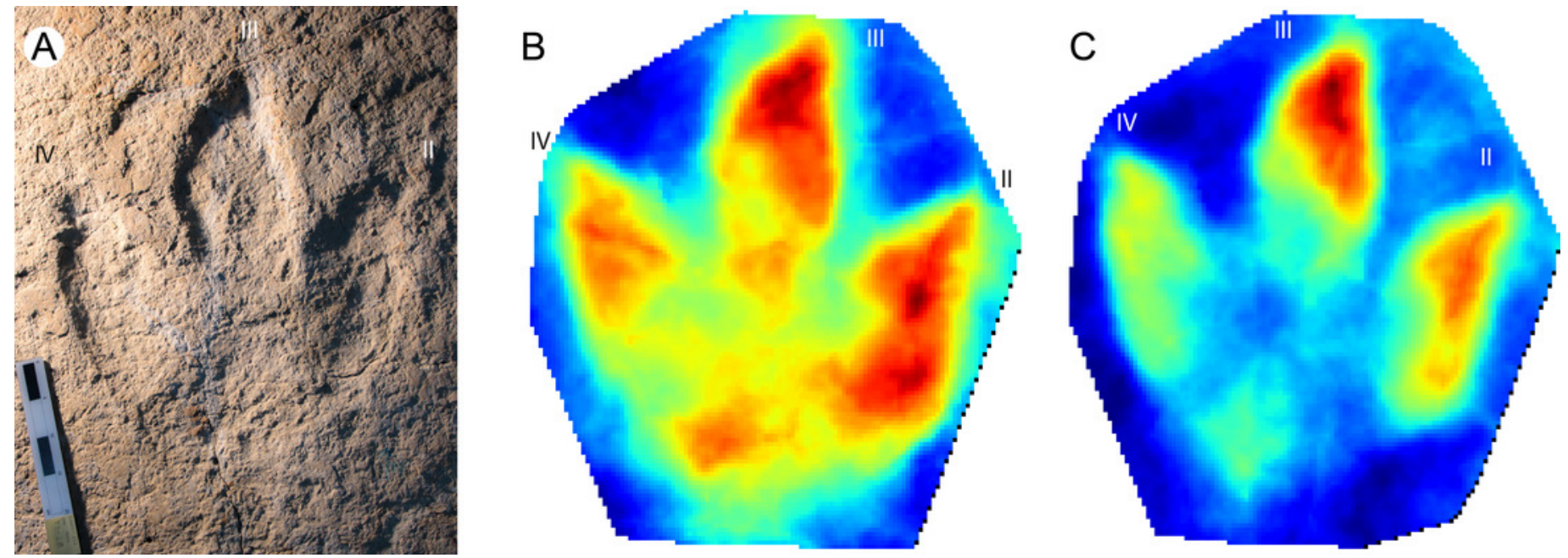


\section{Figure 5}

Megalosauripus transjuranicus photo, mediotype and stat-track

(A) Photograph of the holotype (TCH1030-T6-L1) of the new ichnospecies $M$. transjuranicus.

Scale bar $20 \mathrm{~cm}$. (B) Mediotype generated from the 7 type specimens of $M$. transjuranicus.

(C) Standard deviation stat-track of all 7 type specimens. The colours quantify the deviation among the models along the z-axis (values in mm). "II", "III" and "IV" indicate digit II, digit III and digit IV, respectively. See Table 1 for more information of the specimens used.
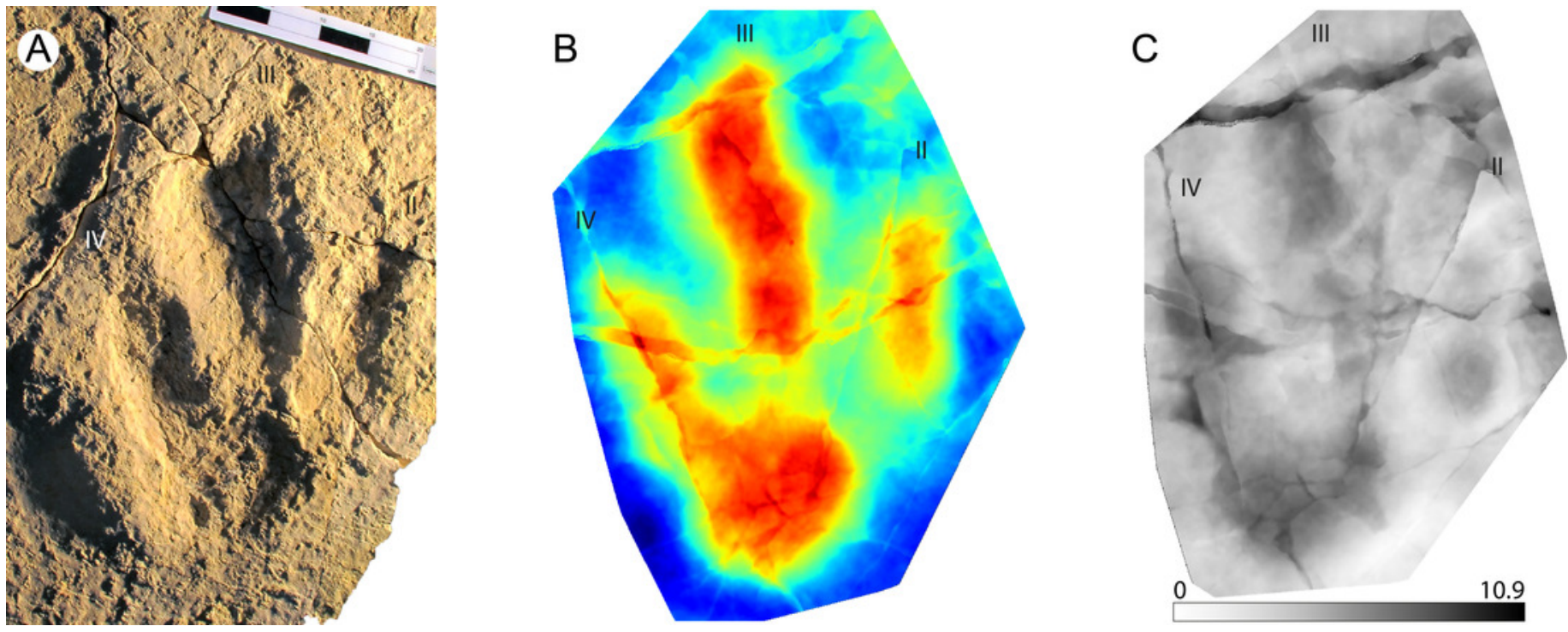


\section{Figure 6}

Examples of taxonomical applications of mediotypes and stat-tracks

(A) Texturized three-dimensional mesh of a Megalosauripus teutonicus track from the Barkhausen tracksite, Germany. (B) Standard deviation stat-track between $M$. teutonicusand $M$. transjuranicus mediotype. The colours quantify the deviation between the models along the z-axis (values in $\mathrm{mm}$ ). (C) Photograph of a megalosaurid track from Morocco (Deio CXXVIII/16 in Belvedere, 2008 and Belvedere, Mietto \& Ishigaki, 2010). (D) Standard deviation stat-track between the Moroccan track and M. transjuranicus mediotype. The colours quantify the deviation between the models along the z-axis (values in $\mathrm{mm}$ ). "II", "III" and "IV" indicate digit II, digit III and digit IV, respectively. See Table 1 for more information of the specimens used.
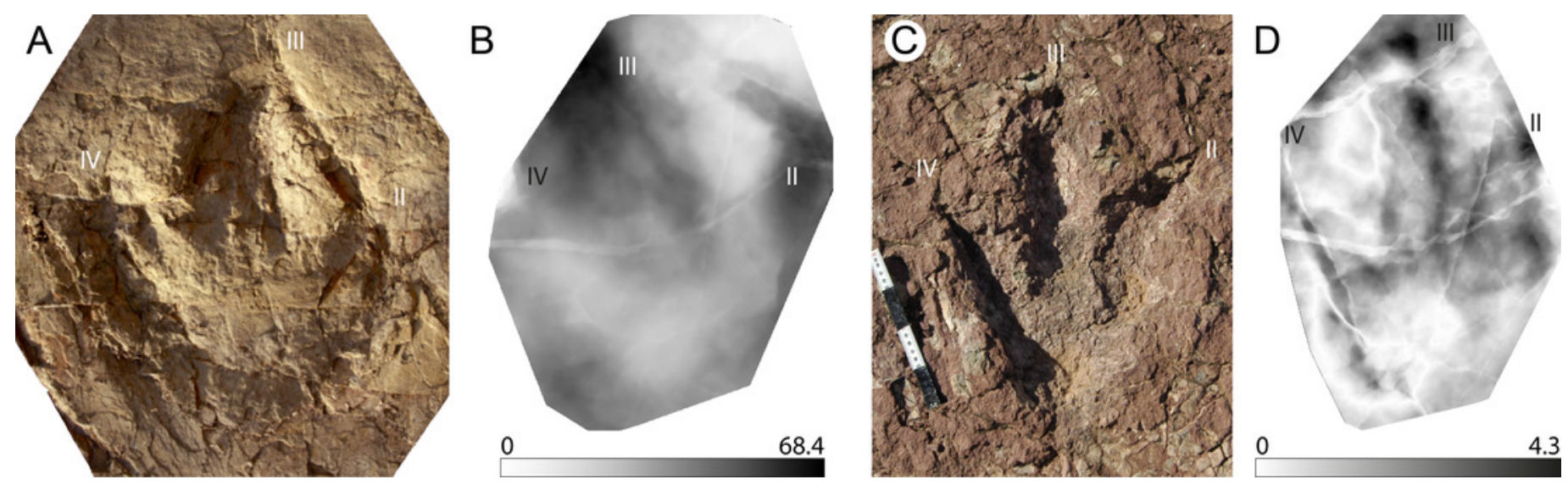


\section{Table $\mathbf{1}$ (on next page)}

Labels and identification numbers of the specimens used for generating stat-tracks and mediotypes

For each figure of this work are reported the number of tracks used to generate stat-tracks and mediotypes, together with their labels. (h) indicated the holotype of an ichnotaxon; ( $p$ ) indicates a paratype of an ichnotaxon. Tracksite abbreviations: BSY: Bois de Sylleux; TCH = Tchâfouè; SCR = Sur Combe Ronde. More information in the Supplementary Information. 


\begin{tabular}{|c|c|c|}
\hline Mediotype & $\begin{array}{l}\text { N. of } \\
\text { tracks }\end{array}$ & Track IDs \\
\hline $\begin{array}{l}\text { Tiny sauropod } \\
\quad \text { (Fig 1a) }\end{array}$ & 10 & $\begin{array}{c}\text { BSY1040-S20-RP8, BSY1040-S20RP9, BSY1040-S21-LP6, BSY1040-S1-RP8, } \\
\text { BSY1040-S2-RP6, BSY1040-S2-LP7, BSY1040-S3-LP3, BSY1040-S3-LP5, } \\
\text { BSY1040-S25-RP1, BSY1040-S6-LP3 }\end{array}$ \\
\hline $\begin{array}{l}\text { Medium sauropod } \\
\text { (Fig 1b) }\end{array}$ & 9 & $\begin{array}{l}\text { BSY1040-S12-LP2, BSY1040-S12-RP2, BSY1040-SS12-LP3, BSY1040-S14- } \\
\text { RP6, BSY1040-S16-LP6, TCH1055-S1-RP3, TCH1055-S1-RP4, TCH1055-S2- } \\
\text { LP2, TCH1055-S5-RP2 }\end{array}$ \\
\hline $\begin{array}{l}\text { Laetoli G1 } \\
\quad \text { (Fig 2) }\end{array}$ & 11 & $\begin{array}{l}\text { G1-23, G1-25, G1-26, G1-27, G1-31, G1-33, G1-34, G1-35, G1-36, G1-37, } \\
\text { G1-39 }\end{array}$ \\
\hline $\begin{array}{l}\text { Laetoli tracks } \\
\quad \text { (Fig 3) }\end{array}$ & 22 & $\begin{array}{c}\text { G1-23, G1-25, G1-26, G1-27, G1-33, G1-34, G1-35(M), G1-36, G1-37, G1- } \\
\text { 39, G2-18, G2-26, G2-27, G2-28, G2-29, L8-S1-1, L8S1-2, L8S1-3, L8S1-4, } \\
\text { TP2S1-1, TP2S1-2, TP2S1-4 }\end{array}$ \\
\hline $\begin{array}{l}\text { J. curtedulensis } \\
\text { (Fig 4b) }\end{array}$ & 4 & SCR1500-T1-L8 (h), SCR1500-T1-L7, SCR1500-T1-R7, BSY1050-TR2-R3 \\
\hline $\begin{array}{l}\text { J. curtedulensis } \\
\text { (Fig 4c) }\end{array}$ & 7 & $\begin{array}{l}\text { SCR1500-T1-R3, SCR1500-T1-L4, SCR1500-T1-R4, SCR1500-T1-L5, } \\
\text { SCR1500-T1-L7 (p), SCR1500-T1-R7 (p), SCR1500-T1-L8 (h) }\end{array}$ \\
\hline $\begin{array}{l}\text { M. transjuranicus } \\
\text { (Fig 5) }\end{array}$ & 7 & $\begin{array}{l}\text { TCH1030-T6-L1 (h), TCH1030-T7-L2, BSY1040-T1-R1, TCH1025-T2-L1, } \\
\text { TCH1030-T2-R2, TCH1030-T2-L3, BSY1035-T6-L2 }\end{array}$ \\
\hline
\end{tabular}

